
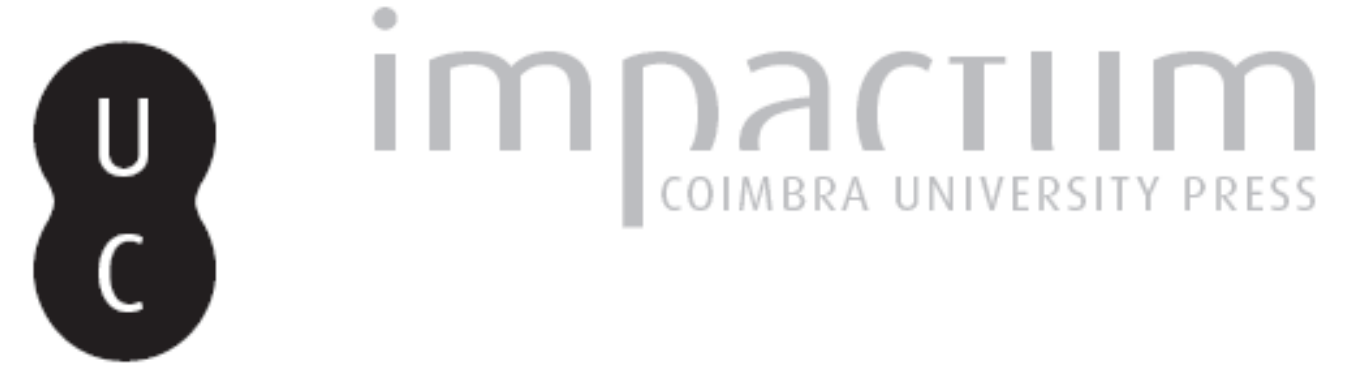

\title{
A dimensão social da União Económica e Monetária Europeia: das suas razões aos instrumentos de concretização
}

Autor(es): $\quad$ Caetano, José Manuel; Rico, Nuno Miguel Publicado por: Centro de Informação Europe Direct de Aveiro; Centro de Estudos

URL

persistente:

DOI: DOI:http://dx.doi.org/10.14195/1647-6336_11_22

Accessed : $\quad$ 26-Apr-2023 11:39:37

A navegação consulta e descarregamento dos títulos inseridos nas Bibliotecas Digitais UC Digitalis, UC Pombalina e UC Impactum, pressupõem a aceitação plena e sem reservas dos Termos e Condições de Uso destas Bibliotecas Digitais, disponíveis em https://digitalis.uc.pt/pt-pt/termos.

Conforme exposto nos referidos Termos e Condições de Uso, o descarregamento de títulos de acesso restrito requer uma licença válida de autorização devendo o utilizador aceder ao(s) documento(s) a partir de um endereço de IP da instituição detentora da supramencionada licença.

Ao utilizador é apenas permitido o descarregamento para uso pessoal, pelo que o emprego do(s) título(s) descarregado(s) para outro fim, designadamente comercial, carece de autorização do respetivo autor ou editor da obra.

Na medida em que todas as obras da UC Digitalis se encontram protegidas pelo Código do Direito de Autor e Direitos Conexos e demais legislação aplicável, toda a cópia, parcial ou total, deste documento, nos casos em que é legalmente admitida, deverá conter ou fazer-se acompanhar por este aviso.

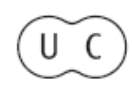


DEBATER

A EUROPA

jul-dez 2014

QUE EUROPA(S)?

CONTEXTOS E DESAFIOS 


\title{
A dimensão social da União Económica e Monetária Europeia:
}

\section{Das suas razões aos instrumentos de concretização}

\author{
José Manuel Caetano \\ Universidade de Évora - Departamento de Economia \\ Membro Associado do CEFAGE-UE, Centro FCT \\ E-mail: caetano@uevora.pt
}

Nuno Miguel Rico

Economista

E-mail: nuno.miguel.rico@gmail.com

\section{Resumo}

A atual crise económico-financeira tem revelado falhas na arquitetura da UEM que não protegeram os Estados mais frágeis no plano económico, tendo os seus efeitos negativos em alguns países da Zona Euro incitado as instituições europeias a reforçarem a União Monetária com uma dimensão social. O presente artigo tem três objetivos: por um lado, identificar imperfeições do atual processo de integração monetária e as razões que justificam a inclusão de uma dimensão social; por outro, reflete sobre as formas e instrumentos que têm sido propostos para concretizar esta vertente social; por fim, trata das iniciativas comunitárias para viabilizar a instituição de mecanismos de apoio financeiro à implementação de reformas estruturais para absorver os efeitos de choques económicos específicos e que melhorem a resiliência da UE.

Palavras-chave: integração económica; União Europeia; dimensão social; solidariedade; reformas estruturais

\begin{abstract}
The current economic and financial crisis has revealed failures in the architecture of EMU that did not protect the most fragile states in economic terms, with its negative effects on
\end{abstract}


some eurozone countries urged the EU Institutions to strengthen the European Monetary Union with a social dimension. This article has three objectives: firstly, to identify flaws in the current process of monetary integration and the reasons that justify the inclusion of a social dimension; second, reflects on the ways and instruments that have been proposed to achieve this social aspect; finally, it deals with the EU initiatives to facilitate the establishment of mechanisms for financial support to the implementation of structural reforms to absorb the effects of specific economic shocks and that improve the resilience of the EU.

Keywords: Economic integration; European Union; Social dimension; solidarity; structural reforms.

\section{Introdução}

Em 9 de maio de 1950, Robert Schuman, Ministro dos Negócios Estrangeiros francês, apresentava uma Declaração sobre um projeto europeu em que, para lá de procurar garantir a paz numa Europa ainda a recuperar dos escombros da $2^{\mathrm{a}}$ Guerra Mundial, deveria promover o relançamento da economia e garantir um desenvolvimento harmonioso dos países, juntando anteriores inimigos. Tal projeto de integração económica, inédito na história mundial contemporânea, desenvolver-se-ia "por meio de realizações concretas que

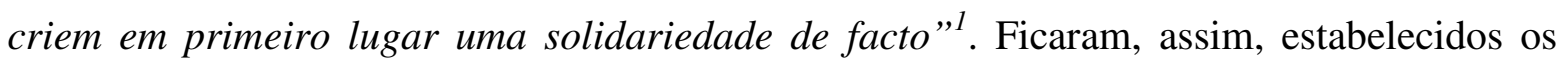
princípios orientadores do que seria a Comunidade Económica Europeia (CEE), a precursora da atual União Europeia (UE) e que procurava, através de realizações concretas de solidariedade e de partilha entre países, promover o bem-estar comum.

O projeto iniciado em 1957 como mera União Aduaneira, em que seis países acordaram abolir as barreiras aduaneiras entre si e estabelecer uma pauta aduaneira única face a países terceiros, transformou-se, após mais de 50 anos, numa União Económica e Monetária (UEM), em que a maioria dos membros da UE partilha a mesma moeda - o Euro. Naturalmente este processo foi acompanhado pela centralização de algumas políticas (monetária e cambial) e pela maior coordenação de outras e, inevitavelmente, por uma significativa transferência de competências e poderes para algumas entidades supranacionais que foram sendo criadas.

\footnotetext{
${ }^{1}$ Declaração de Robert Schuman de 9 de Maio de 1950 (disponível no site da Comissão Europeia).
} 
Não obstante algumas fases de marasmo e mesmo retrocesso, este projeto de integração económica tem tido sucesso, podendo ser considerado um fator de desenvolvimento económico e social dos seus Estados-membros. Esta dinâmica estendeu-se, inclusive, a países não membros, derivado das sinergias criadas e que contribuíram para uma expressiva estabilidade política e melhoria das condições económicas e sociais na parte mais ocidental da Europa.

Através da criação de um conjunto de políticas comunitárias, das quais se destacam as Políticas Estruturais e de Coesão, a UE contribuiu para o desenvolvimento dos seus membros nas últimas décadas, apesar da convergência real entre os seus membros não ter progredido de forma muito significativa (Borsi and Metiu, 2013). Não obstante este facto, o nível de vida dos cidadãos nos países da UE melhorou gradualmente, reforçando o sentimento de pertença a um projeto comum. Os sucessivos alargamentos atestam os benefícios que os países ambicionam com a sua participação neste projeto comum. Todavia, a crise económico-financeira mundial que desde 2007 vem fustigando os países da UE, em particular alguns da zona Euro, tem provocado sintomas inquietantes de contestação ao projeto europeu.

$\mathrm{Na}$ realidade, esta crise iniciou-se nos Estados Unidos mas rapidamente mudou o centro de gravidade para a Europa e veio mostrar a fragilidade de algumas destas economias, mormente os elevados níveis de endividamento público de países da zona Euro e os efeitos de tal situação na sua sustentabilidade económico-financeira e da própria moeda única, o que aconselhava tirar lições para o futuro (Angeloni, et. al., 2013). A crise tornou também patente a fraca convergência entre os níveis de desenvolvimento económico dos Estadosmembros, evidenciando divergências estruturais persistentes no processo de integração económica europeia.

Outro facto relevante confirmado pelo desenrolar dos acontecimentos foi a débil e tardia reação à crise por parte das instituições comunitárias, evidenciando os limites da estrutura funcional e organizacional da UEM, o que confirmou os receios e as advertências de variados autores sobre a viabilidade do projeto da moeda única. De forma abundante a teoria económica tem demonstrado que numa zona monetária ${ }^{2}$ em que vários países partilham a mesma moeda, sempre que algum destes seja sujeito a um choque económico específico a capacidade do ajustamento dependerá do grau de mobilidade laboral, da

\footnotetext{
${ }^{2}$ A este propósito Mundell publicou em 1961 um estudo seminal intitulado "A Theory of Optimum Currency Areas", onde elabora sobre as condições para garantir a criação de uma zona monetária ótima, o qual continua a ser uma referência fundamental neste domínio.
} 
flexibilidade dos mercados de bens e serviços e de fatores, ainda, do eventual efeito estabilizador da política orçamental.

Deste modo, uma zona monetária eficaz deve possuir condições para, por um lado, permitir o rápido ajustamento dos países que forem afetados pelos referidos choques e, por outro, deve dispor de meios para evitar os riscos de alastramento dos efeitos entre os seus membros. Esta posição recomenda a existência de um dispositivo orçamental centralizado que permita intervir de forma rápida para estabilizar a economia e acomodar os custos de ajustamento, evitando o alastramento dos efeitos aos parceiros e facilitando o reequilíbrio económico.

Quando analisamos o caso da atual UEM verificamos que a maioria daquelas condições não se verifica, o que pode pôr em causa a sua própria estabilidade e a dos seus membros. Na realidade, regista-se ainda uma reduzida mobilidade do trabalho entre os países da UE, sendo que em alguns destes os mercados laborais denotam a permanência de fatores de rigidez no seu funcionamento, o que reduz a capacidade para ajustar num prazo curto. Não é de estranhar que, perante tais lacunas estruturais, os países sujeitos a condições financeiras e económicas adversas tenham sentido sérias dificuldades em encetar uma sólida recuperação, ao mesmo tempo que iam surgindo externalidades negativas nos restantes parceiros da zona Euro.

Perante este cenário, avolumaram-se as assimetrias no seio da Zona Euro, revelando diferentes níveis de desempenho económico dos países, o que motivou que as consequências da crise se tivessem repercutido com diferentes intensidades nas várias economias. De igual modo, a capacidade de resposta diferiu significativamente entre países, pelo facto de o regime da moeda única limitar o leque de políticas disponíveis para combater as consequências económicas e sociais da crise.

À medida que os efeitos da crise económico-financeira se foram agravando nos países mais vulneráveis da Zona Euro e os efeitos da austeridade afetaram os estratos sociais menos protegidos, intensificaram-se os incitamentos de vários setores para que o projeto da UEM incluísse uma dimensão social, em complemento das vertentes económica, orçamental, bancária e política. A introdução deste novo pilar decorria da constatação que a UEM teve falhas no seu figurino institucional que não protegeu os membros economicamente mais frágeis. Assim, as consequências negativas que alguns países vêm sofrendo ameaçaram os seus sistemas sociais, além de colocarem em causa os objetivos últimos do processo de integração europeia. 
Foi neste contexto que os presidentes de quatro instituições comunitárias apresentaram em finais de 2012 o relatório "Rumo a uma verdadeira União Económica e Monetária" que teve o mérito de introduzir no debate político novos elementos para assegurar a estabilidade e a integridade da zona Euro. O documento indiciou uma autocrítica às falhas da UEM, as quais foram evidentes quando a zona Euro ficou exposta ao risco da dívida soberana em alguns dos seus membros.

Sucederam-se outras iniciativas institucionais, de que realçamos o reconhecimento por parte dos líderes europeus de que uma UEM como a zona Euro, por si só, era incompleta. Assim, tornava-se necessário incluir novas vertentes, mormente a dimensão social, cujo corolário até agora aconteceu com a publicação em outubro de 2013 da Comunicação da Comissão denominada "Reforçar a dimensão social da União Económica e Monetária” (Comissão Europeia, 2013-a).

Nesta perspetiva, o presente artigo tem três objetivos: por um lado, procura identificar algumas imperfeições do atual processo de integração monetária e as razões que justificam a inclusão de uma dimensão social; por outro, aborda as propostas institucionais que estão em discussão para concretizar esta vertente social, tendo em conta a necessidade de conciliar a dimensão social da UEM com o já adquirido património da "Europa Social; por fim, discute as iniciativas para viabilizar a instituição de mecanismos de apoio financeiro para apoiar a implementação de reformas estruturais e a absorção de efeitos de choques específicos, no sentido de melhorar a sua resiliência social e económica.

\section{A crise financeira no contexto de uma União Monetária Europeia incompleta}

Distintos quadros teóricos têm sido usados para fundamentar as soluções institucionais para escolher um modelo de UEM. De entre os vários enfoques, a já referida teoria de Mundell tornou-se uma referência clássica. Esta teoria admite que para aproveitar as vantagens de uma moeda comum num grupo de países, estes deverão dispor de uma elevada simetria económica e uma forte sincronização dos seus ciclos económicos. Acontece que no caso da zona Euro as assimetrias nas estruturas e nos ciclos económicos permanecem, ao mesmo tempo que a coordenação orçamental e a integração fiscal se mantiveram a níveis incipientes.

De facto, o conjunto de regras para coordenar e disciplinar variáveis orçamentais nos países da UEM tiveram enquadramento formal nas duas versões do Pacto de Estabilidade e Crescimento (PEC), a primeira em 1997 e a segunda em 2005. O PEC procurava então que 
os Estados assumissem um compromisso forte com a disciplina orçamental, procurando evitar políticas fiscais expansionistas que pudessem por em causa a estabilidade macroeconómica.

Numa primeira fase, o PEC ainda promoveu aparentemente uma tendência de sustentabilidade das finanças públicas nacionais, porém, em 2003 a sua credibilidade e das instituições comunitárias foi seriamente abalada quando países como França e Alemanha viram suspensa a aplicação das regras que implicavam penalizações financeiras de vulto depois de terem registado uma deterioração dos seus défices orçamentais para lá dos limites estipulados (Caetano e Sousa, 2012). Posteriormente, em 2005, algumas regras do PEC foram alteradas, alegando a necessidade de conceder maior flexibilidade ao instrumento, mas os resultados obtidos, segundo Schuknecht et. al. (2011), não tiveram grande efeito sobre as trajetórias das finanças públicas dos países da zona Euro.

Não obstante a fraca credibilidade e reputação do PEC, formalmente os países pertencentes à zona Euro continuam sujeitos à disciplina orçamental, o que implica uma limitação relevante para as políticas fiscais nacionais sempre que tenham que reagir perante situações de choques económicos, para lá da impossibilidade de utilizar a política monetária e cambial que passou a ser definida pelo Banco Central Europeu (BCE) desde a criação do Euro em 1999.

É devido a este conjunto de limitações às políticas económicas nacionais e às interações que entre elas se estabelece que a simetria e convergência económica entre os seus membros se torna fulcral para garantir a estabilidade do sistema. A ausência de simetria não salvaguarda a ocorrência de choques assimétricos, os quais podem aprofundar as divergências económicas entre os países e por em causa o processo de integração. Os instrumentos existentes para responder a choques económicos exógenos, como os ocorridos após 2008, eram limitados e apenas possíveis de ser aplicados através de políticas comuns, as quais podem produzir efeitos díspares quando as economias estão em diferentes patamares de consolidação financeira.

Quando, em setembro de 2008, ocorreu a falência de um dos maiores bancos nos Estados Unidos, o Lehman Brothers, provocando a designada crise do subprime, não eram imagináveis na UE as implicações que este facto despoletaria na sua economia. Com efeito, a consequente crise económica que se instalou nos EUA rapidamente alastrou à Europa, provocando uma enorme instabilidade nos mercados financeiros europeus e mundiais que colocaram em causa a solidez e viabilidade de muitas instituições financeiras europeias, também elas detentoras de significativo volume de crédito de cobrança duvidosa nos seus 
portefólios e com elevados montantes de crédito concedidos aos governos dos EstadosMembros.

Cremos ser útil revisitar a forma titubeante e algo errática como as instituições europeias lidaram com a crise e que, em nossa opinião, acabou por se revelar pouco eficaz. Não obstante o Conselho Europeu (CE) de março de 2008 ter considerado que a economia da UE permanecia sólida, era já identificada alguma instabilidade nos mercados financeiros devido à degradação da situação externa. Todavia, após a falência do Lehman Brothers, o CE em outubro de 2008 reconheceu que a crise nos mercados financeiros poderia constituir uma séria ameaça à estabilidade do sistema financeiro.

Em conformidade com o estudo realizado pelo Centro de Estudos Sociais (2013:73) a UE em 2008 esteve confrontada com a fase financeira da crise, caracterizada pela focalização exclusiva do Conselho Europeu em escapar ao colapso do sistema financeiro na Europa. Neste período, os rácios de endividamento dos Estados-Membros mais vulneráveis dispararam, fazendo com que os mercados financeiros pusessem em causa a sustentabilidade da dívida destes países, despoletando o que ficou conhecido como a "Crise das Dívidas Soberanas", que acabou por colocar em causa a viabilidade do Euro.

A situação evoluiu posteriormente de forma muito rápida, pelo que no $\mathrm{CE}$ de dezembro de 2008 foi já mencionada a existência de uma crise económica e financeira à escala global que exigia resposta coordenada para precaver a eventual recessão económica. Assim, em simultâneo com o prosseguimento dos resgates aos bancos em dificuldades, a UE entrou na fase expansionista do combate à crise, através da ativa mobilização das políticas orçamentais. Porém, esta fase que se revelou excecional na estratégia seguida acabou também por ter uma curta duração.

Na realidade, perante os primeiros ténues sinais de recuperação em alguns países da zona Euro no início de 2010 o foco voltou de novo para a contenção das finanças públicas, para a preservação da integridade do Euro e para o retorno da confiança aos mercados, através das políticas do enfase na consolidação orçamental coordenada pela UE. Entrávamos então na fase da austeridade que concretizaria uma estratégia para o regresso à normalidade, sem ter esperado que os sinais de recuperação económica se generalizassem aos vários países.

Ora, foi nesta fase, em que os responsáveis europeus procuravam garantir a sustentabilidade do Euro, que Grécia, Irlanda e Portugal deixam de ter acesso aos mercados para o financiamento da sua dívida soberana. Porém, nem mesmo perante tais sinais, a crise 
passou a ser encarada pelas instituições europeias como tendo origem nas deficiências na arquitetura da moeda única. De facto, a crise continuou a ser vista como uma crise da dívida soberana dos seus membros e que era o produto da indisciplina orçamental de alguns países, apesar do iminente risco de contaminar a Zona Euro e comprometer a sua estabilidade. Desta assunção decorre uma orientação para o reforço da disciplina orçamental na UE e a subsequente sujeição dos países periféricos a penosos programas de austeridade para reequilibrar as suas finanças públicas e fazer o seu ajustamento.

Cremos ser essencial abordar com algum enquadramento teórico a filosofia subjacente aos programas de ajustamento da "Troika"3 aplicados na Grécia, Irlanda e Portugal após 2010, os quais constituem uma novidade pois têm por alvo países há muito integrados nos mercados financeiros mundiais e, acima de tudo, inseridos numa União Monetária. Ora, desta última circunstância decorrem condicionalismos distintos dos que se aplicam aos países que dispõem de autonomia nas suas políticas cambiais e monetárias, o que de certa forma tem contribuído para escrutinar mais atentamente os resultados daquelas intervenções e também para identificar com mais rigor as eventuais falhas na conceção da UEM para responder a situações desta natureza.

Autores como Laeven and Valencia (2012), analisaram as distintas expressões assumidas pelas crises financeiras e as interações funcionais que entre elas se estabelecem, o que é relevante para aferir as especificidades da sua ocorrência no seio de uma UEM. De acordo com aqueles autores a turbulência financeira pode ter origem em três tipos de crises: bancárias, soberanas e da Balança de Pagamentos (BP).

Em primeiro, as crises bancárias podem ocorrer em qualquer regime cambial e monetário e no caso da Zona Euro deveria ter sido prevista uma instituição para desempenhar o papel de "prestamista de último recurso", no sentido de assegurar a liquidez e resguardar os Estados confrontados com situações de crise e evitar o contágio entre a dívida dos bancos e a posição dos Estados. Acontece que os bancos centrais dos países da zona Euro já não dispunham desta prerrogativa e o BCE não exerceu em pleno aquela função desde o início do processo, pelo que a reduzida coordenação das intervenções não permitiu evitar o risco de contágio (Véron, 2007).

Em segundo, no que à crise da dívida soberana respeita, a maior dificuldade colocada por uma UEM decorre da proibição de financiamento monetário da dívida pública,

\footnotetext{
${ }^{3}$ Designação dada às instituições que financiaram os programas de resgate financeiro aos países periféricos e que integra o Fundo Monetário internacional, o Banco Central Europeu e a Comissão Europeia.
} 
reconhecendo-se que só a eficaz vigilância centralizada sobre a sustentabilidade da dívida poderia impedir situações mais problemáticas. Porém, na arquitetura da UEM não existia qualquer estrutura capaz de desempenhar com sucesso a função de gestão de crises (Eichengreen and Wyplosz, 1998). É um facto que ocorreu uma forte integração dos mercados financeiros após a criação do Euro, mas a responsabilidade pela supervisão prudencial e gestão de crises permaneceu a nível nacional, tendo resultado desta assimetria uma desadequada coordenação e fraca capacidade de resposta.

Finalmente, havia entendimento das instituições comunitárias que as crises da BP teriam pouca probabilidade de acontecer numa UEM, dado que nesta situação os países asseguravam a sua solvência com recurso a financiamento privado não ficando expostos a ataques especulativos. De facto, já no relatório da Comissão Europeia “One Market, one Money" que lança as bases para a criação da moeda única, era reconhecido que com a criação da UEM as restrições decorrentes da BP deixariam de pesar sobre os países da zona monetária (Comissão Europeia, 1990).

Não obstante a experiência acumulada a lidar com crises financeiras, Pisani-Ferry et. al. (2011) concedem que as entidades que integravam a "Troika" não estavam preparadas para uma situação de crise de dívidas soberanas e de BP no seio da zona Euro. A crise é espoletada quando os mercados deixam de financiar os projetos viáveis devido à situação do país onde tais projetos se localizam. De facto, os Estados, enquanto garante último da solvabilidade dos agentes sob sua jurisdição, em especial os bancos, centralizam os riscos por estes assumidos. Em simultâneo, os bancos com carteiras de ativos pouco diversificadas acumulam riscos resultantes da eventual insolvência dos seus clientes, entre os quais o próprio Estado. Como os países do Euro emitem dívida numa moeda que não controlam, não podem garantir aos detentores dos títulos que assegurarão o seu reembolso na maturidade (De Grauwe, 2011), expondo os países a crises de liquidez que podem ser desencadeadas por quebras de confiança dos mercados.

Esta interdependência entre Estado, bancos e agentes não financeiros pode levar à subida do risco do país, penalizando os agentes com maiores custos de financiamento da sua atividade. No contexto da crise do subprime, os mercados financeiros reavaliaram a exposição face aos países da zona Euro que acumularam maiores défices orçamentais e na BP e aumentaram os respetivos prémios de risco nos empréstimos, o que restringiu fortemente o acesso destes países ao crédito. Assim, o setor privado deixou também de aceder ao crédito a taxas de juro atrativas, o que gerou efeitos em cadeia sobre a estrutura produtiva e afetou o crescimento económico. Neste cenário, perante a rápida subida dos 
custos de financiamento, os países em maior dificuldade solicitaram ajuda financeira externa e aceitaram os consequentes programas de ajustamento.

Em suma, a especificidade destes casos resulta da conjugação de regimes de paridades cambiais fixas com total mobilidade de capitais, o que, perante a restrição de nãomonetarização da dívida e a necessidade de ajustar a BP, colocou os Estados em situação de penúria de liquidez e sem meios de intervenção. Exigiam-se disposições de condicionalidade diferentes das que foram definidas pela assistência financeira internacional, em especial das entidades comunitárias envolvidas, pois a principal lacuna tinha a ver com as restrições ao financiamento da dívida soberana, já que a questão da BP acabou gradualmente por ser garantida por via do financiamento do Eurosistema.

Em situações tradicionais o ajustamento por via cambial e monetária contribui para a redução da taxa de câmbio real (TCR) até um nível consistente com o retorno ao equilíbrio externo. Porém, na impossibilidade de usar tais políticas no caso dos países integrados na zona Euro, a recuperação da competitividade externa, através da desvalorização da TCR, recaiu sobre as variáveis que provocaram o ajustamento dos custos reais, o que tornou o processo de desvalorização interna bastante penoso no plano social como veremos de seguida.

\section{Dos impactos económicos da crise à necessidade de uma dimensão social na UEM}

Em virtude da indisponibilidade das políticas de desvalorização cambial, os programas de ajuda financeira externa aplicados aos países do Euro confrontaram-se com um referencial inédito e que implicava o ajustamento dos défices externo e orçamental por outras vias, o que exigia soluções distintas das usualmente aplicadas. Já Blanchard (2007) reconhecia, na abordagem à questão de uma eventual crise na BP em Portugal, que um resultado equivalente a uma desvalorização cambial poderia ser alcançado pela redução dos salários nominais e dos preços dos bens não transacionáveis.

Deste modo, o autor previa que a viabilidade de uma estratégia de "desvalorização interna" estaria dependente da resistência das organizações sindicais, mas não vislumbrava outra alternativa devido ao baixo crescimento da produtividade, à agudização do défice comercial com o exterior e ao alastramento das situações de desemprego. Sugeria, ainda, o eventual recurso à política orçamental para minorar os efeitos recessivos na procura interna, antevendo os consequentes efeitos negativos sobre o poder de compra da população. 
Todavia, a intervenção da "Troika" nos países do Euro não se adequava de forma exata ao que Blanchard na altura adiantara, pois o enfoque que a UE colocava na consolidação das finanças públicas não admitia o recurso a políticas orçamentais anticíclicas, já que, em simultâneo com o controlo do défice externo, pretendia-se assegurar a sustentabilidade da dívida pública. Era de facto uma estratégia com elevados riscos, até porque os precedentes históricos invocados como casos de sucesso em situações semelhantes não tinham acontecido em contextos de crise económica generalizada como a que vinha ocorrendo desde 2007.

Os referidos programas de ajustamento, em especial o dedicado a Portugal, foram orientados para provocar, em simultâneo, a desvalorização interna e o ajuste orçamental, implicando a descida nos salários do setor público e nas pensões, o que, face à progressiva erosão da capacidade negocial dos sindicatos, criaria condições para proceder à reforma laboral. Todavia, os maiores riscos desta estratégia tinham a ver com a forte possibilidade dos efeitos recessivos e das suas implicações económicas e sociais serem muito superiores ao expectável ${ }^{4}$.

Como os anos seguintes comprovaram, a dureza e a longevidade da recessão económica associada aos programas de austeridade deixaram marcas indeléveis no tecido económico e no plano social dos países alvo de intervenção externa. Teoricamente admite-se que na fase inicial de uma recessão, os agentes económicos procurem ajustar os comportamentos de consumo e poupança, podendo até esta estratégia de adaptação gerar algum sucesso em prazo curto.

Porém, com o agravar das medidas de austeridade, os efeitos recessivos foram aumentando, o que propiciou um encadeamento de impactos negativos sobre o tecido empresarial e a erosão do poder aquisitivo dos consumidores. Noutra vertente, as características estruturais do desemprego, como o excessivo prolongamento da inatividade que afeta as capacidades e a motivação das pessoas e, ainda, a proliferação do desemprego jovem, o qual alimenta o fenómeno migratório e incita a saída de pessoas jovens qualificadas, contribuíram fortemente para reduzir a vitalidade do tecido económico.

Deste modo, sem surpresa verificou-se que nos países periféricos da zona Euro, o PIB caiu vários pontos percentuais, levando ao aumento de falências de empresas e ao

\footnotetext{
${ }^{4}$ Curiosamente autores como Alesina e Ardana (2009) defendiam esta estratégia, convictos de que a consolidação orçamental promoveria benefícios sobre a expansão da actividade económica. A experiência no caso dos países intervencionados pela "Troika" mostra que tais benefícios estão longe de se registar.
} 
inerente incremento exponencial do desemprego ${ }^{5}$ e dos níveis de pobreza. O rendimento disponível das famílias reduziu-se de forma drástica, voltando, em alguns casos, a valores inferiores aos do início do século. Os governos nacionais limitaram bastante as suas despesas, nomeadamente ao nível social, procurando cumprir as metas para as Contas Públicas definidas nos programas de ajuda. Adicionalmente, deixaram de possuir condições financeiras para aplicar medidas de estímulo à economia, no sentido de promover uma mais rápida recuperação.

Este processo de "desvalorização interna" acentuou-se, através da progressiva deterioração dos custos do trabalho, já que, incitado pelo aumento do desemprego, assistiuse a uma forte redução dos salários nos países sujeitos a resgate financeiro. Esta compressão dos salários foi socialmente gravosa, pois em paralelo ao aumento do desemprego, cresceu o risco de pobreza e o fenómeno de exclusão alastrou nos estratos sociais mais desfavorecidos. Este processo, sem precedentes na história de muitos países após sua adesão à UE, resultou no retrocesso económico e social para valores registados há mais de uma década, provocando agitação social e contestação em alguns países e até hostilidade para com o processo de integração europeia.

Acresce que, em virtude do Mercado Único Europeu e da livre circulação de pessoas e fatores que este consagrou e viabilizou, os efeitos não ficaram limitados aos países inicialmente mais afetados e estenderam-se um pouco por toda a UE. A recuperação da competitividade através da redução da proteção social, associada a um aumento dos movimentos migratórios, levou a que alguns países tomassem medidas similares no sentido de resguardar a sua competitividade. Assistiu-se então a alguns fenómenos de "nivelamento por baixo" das normas e políticas sociais no seio da UE, ameaçando produzir efeitos nefastos sobre os modelos sociais dos seus membros. Assim, o que começou por ser uma questão nacional dos países com maiores dificuldades para assegurar o financiamento da sua Dívida, tornou-se um problema transversal a toda a UE.

Esta reação defensiva de alguns Estados (Maslauskaite, 2013), consagrada na literatura como "dumping social", permitiu que as economias readquirissem alguma competitividade nas suas exportações, em consequência da redução dos custos de produção, registando uma melhoria nos respetivos saldos na Balança Comercial ${ }^{6}$. Todavia, tais

\footnotetext{
${ }^{5}$ Ver o documento "EU Employment and Social Situation, Special Edition: Annual Overview" da Comissão Europeia publicado em 2013.

${ }^{6}$ Há também indícios de que a recuperação dos saldos da Balança Comercial em algumas situações decorreu mais da redução das importações, na sequência da contração da procura face às políticas de austeridade, do que propriamente dos efeitos positivos sobre a dinâmica das exportações.
} 
medidas, a médio e longo prazo, ficarão inevitavelmente associadas às severas consequências sociais que provocaram, sobretudo nos grupos mais desprotegidos e que pode levar a um processo cumulativo de empobrecimento, acentuando as assimetrias já existentes no seio da UE.

Por via das reduções salariais e dos benefícios sociais e, ainda, pela facilitação dos processos de despedimento, os países modelaram a efetiva desvalorização das suas economias, procurando resultados similares aos que teriam origem na depreciação da moeda nacional, como forma de impulsionar a competitividade, mas com consequências sociais mais drásticas. O agravamento do desemprego, decorrente da redução da procura interna e da designada flexibilização do mercado laboral, contribuiu para a redução dos rendimentos familiares, colocando milhares de pessoas em situação de emergência social, em especial nos países periféricos.

Para lá das consequências económicas e sociais, ocorreu ainda uma outra tendência que pode condicionar a sustentabilidade futura do processo de integração europeia. Assistimos, desde o início da crise, a uma maior clivagem entre os países do centro e norte da Europa em relação aos países periféricos, a qual é patenteada, não só pelas consequências económicas e sociais da crise, mas principalmente na capacidade de reagir e recuperar desta situação ${ }^{7}$.

Não sendo questão nova no debate europeu a dimensão social da Europa, em especial na zona Euro, tornou-se pertinente e iniludível no plano político-institucional. Os impactos sociais da crise económica e das políticas de austeridade promoveram a desregulação e a redução da proteção social, lançando alguns países numa espiral de empobrecimento que ameaça pôr em causa o apoio das populações ao projeto europeu e o reconhecimento da sua legitimidade. A evolução da crise na zona Euro mostrou de forma impressiva a existência de um grande "défice social" no projeto e que as instituições comunitárias não estavam preparadas para dar uma resposta global e eficaz à situação com base nos meios e instrumentos que dispunham.

De forma breve procuraremos sintetizar os argumentos de natureza funcional e política que fomos referindo ao longo desta secção e que justificam a necessidade de desenvolver uma vertente social para completar a arquitetura da UEM. Partilhamos a visão

\footnotetext{
${ }^{7}$ Esta crescente divergência entre os países da UE é visível no estudo da revista The Economist: "European Economy Guide: Taking Europe's Pulse” publicado em 2014.
} 
de Fernandes e Maslauskaite (2013) que identificam dois grupos de motivações maiores para a inclusão desta dimensão social.

Uma primeira linha de argumentação tem natureza funcional e reconhece que a ausência de simetria económica no seio da zona Euro provou ser forte condicionante ao seu eficaz funcionamento, tendo a evolução ao longo da crise demonstrado que os choques assolaram de forma bastante mais intensa os países mais frágeis. Tal significou que, no plano prático, a UEM não produziu os resultados previstos com a sua criação, tendo-se refletido numa superior divergência económica entre os seus membros

Deste modo, uma dimensão social promoverá o melhor funcionamento da UEM se contribuir para a superior sincronização dos ciclos económicos com recurso à supervisão e coordenação das políticas macroeconómicas, concorrendo para reduzir as diferenças estruturais entre países. Acresce que uma melhor convergência das políticas sociais, num sentido mais lato que abranja domínios como a educação e a formação, pode melhorar a simetria entre os países ao intervir em áreas determinantes para a sua competitividade. Também, o reforço da mobilidade laboral no seio da UE poderia amortecer as consequências sociais do desemprego, mas acontece que neste caso os valores são bastante reduzidos, registando-se que só cerca de 3\% dos europeus em idade ativa vivem em outro país da União (Fernandes e Maslauskaite, 2013:6).

Um segundo conjunto de razões é de natureza mais política e tem a ver com a necessidade de contrariar a convicção que se vai generalizando de que o Euro está a minar as bases dos sistemas nacionais de segurança social, por via da maior pressão da competição entre Estados-membros no domínio social com o propósito de preservar a sua competitividade. Naturalmente um certo grau de concorrência entre os Estados, quando orientada para a melhoria da qualidade, pode ser salutar, mas quando se trata de um abaixamento das normas sociais entramos num domínio delicado que pode abalar os alicerces dos modelos sociais existentes em cada país.

A crença de que grande parte do ajustamento orçamental tem sido feito á custa de um crescente desinvestimento público nos sistemas de proteção social, permite questionar a viabilidade social do processo de ajustamento. Deste modo, o reforço da dimensão social com a criação de normas comuns e uma maior capacidade de intervenção centralizada sobre fenómenos como o desemprego jovem ou o aumento da pobreza, bem como o apoio financeiro para a aplicação de reformas estruturais, pode ajudar a refazer um sentimento de comunhão com o projeto europeu. 


\section{Iniciativas institucionais em prol do reforço da dimensão Social na zona Euro}

A redução do apoio dos cidadãos europeus ao projeto de integração tem sido notória, com um crescente apoio aos partidos e movimentos antieuropeístas e o aparecimento de personalidades académicas e políticas a defenderem a saída de países da zona Euro como forma de ultrapassar os problemas económicos e sociais que os afetam ${ }^{8}$. As consequências sociais da crise vieram reintroduzir na agenda política a importância da questão social nos assuntos comunitários, pois se é certo que a estabilidade económica e orçamental é vital para a credibilidade da moeda única, também não podemos descurar que a estabilidade social é crucial para a construção europeia.

A preocupação com as questões sociais sempre esteve presente nas políticas comunitárias. Logo em 1958 foi criado o Fundo Social Europeu (FSE) que pretendia apoiar as políticas de promoção do emprego e de formação profissional principalmente nos países e regiões mais desfavorecidos. Seguiu-se a Política de Coesão que foi decisiva no auxílio à convergência económico-social dos países mais pobres da União. Todavia, a necessidade de assegurar maior convergência tornou-se ainda mais importante num contexto do Mercado Único e da UEM, devido às sucessivas vagas de liberalização dos fluxos na UE é à gradual limitação dos instrumentos e políticas disponíveis para os governos nacionais intervirem nas suas economias.

Após a criação do Euro tem-se verificado uma dominância das questões financeiras face aos aspetos de natureza social, até porque a intervenção mais específica sobre estes domínios continuou remetida para a quase exclusiva competência dos Estados nacionais. Nos anos mais recentes, em consequência da crise e da inerente necessidade de ajustamento, têm vindo a ser tomadas medidas com implicações sociais relevantes para as populações mais desprotegidas, o que tem gerado um crescente descontentamento e um sentimento de desagregação no seio da UE.

Atentos a esta situação, os líderes europeus começaram a dar sinais sobre a necessidade de intervir de forma mais direta em outras dimensões que o decorrer da crise patenteou, procurando corrigir algumas lacunas no funcionamento da UEM. O primeiro passo nesse sentido foi o chamado Relatório dos 4 Presidentes (também designado por

\footnotetext{
${ }^{8}$ Ver, por exemplo, Amaral (2013), onde o autor argumenta sobre a inevitabilidade de Portugal abandonar o Euro para resolver o seu problema de competitividade externa.
} 
relatório Quadriga) ${ }^{9}$, apresentado em 2012, que procurou lançar a discussão no Conselho Europeu, no sentido de criar uma verdadeira união económica. Esta primeira diligência constituiu um marco essencial no sentido de preparar um roteiro específico para completar a UEM, admitindo de forma explícita a necessidade de tomar iniciativas complementares em vários níveis.

Neste encadeamento, a Comissão Europeia apresentou posteriormente o que designou por plano pormenorizado para uma efetiva $\mathrm{UEM}^{10}$, destacando a necessidade de manter o atual figurino institucional e jurídico e respeitar a integridade do mercado único, a fim de criar um quadro sólido para a zona Euro e uma relação transparente para com os demais países da UE. Em dezembro de 2012 os líderes das quatro instituições comunitárias apresentaram novo relatório ${ }^{11}$ com um conjunto de iniciativas para assegurar a estabilidade e a integridade da UEM, apelando a um vigoroso impulso político e laborioso trabalho legislativo para o implementar. O documento identificava um conjunto de falhas na arquitetura da UEM, as quais terão propiciado o acumular dos efeitos da crise e que acabou por questionar a própria viabilidade do Euro.

$\mathrm{O}$ roteiro então proposto apontava para um plano faseado em que, num primeiro momento, a prioridade seria estancar a ligação entre os sistemas bancários e os Estados e assegurar a sustentabilidade orçamental, a que se seguiriam ações para criar um quadro financeiro integrado e promover reformas estruturais nos Estados-membros, sendo mencionada a possibilidade de apoio financeiro transitório da UE a alguns países. Finalmente, num horizonte pós-2014 e sujeito a alterações nos Tratados, seria criado um mecanismo financeiro comum para ajudar os países sujeitos a choques económicos específico para melhorar a resiliência da UEM.

Houve, assim, um reconhecimento implícito de que o bom funcionamento da UEM exigia bases mais sólidas, as quais deviam passar por uma união orçamental e uma união bancária, ancorando um novo regime de governação económica na zona Euro. Na base deste plano o Conselho Europeu assumiu compromissos e tomou decisões com o intuito de resolver a crise económica e financeira e relançar o projeto de construção europeia (Conselho Europeu, 2012).

\footnotetext{
${ }^{9}$ Envolvendo as seguintes instituições comunitárias: Conselho Europeu, Comissão Europeia, Eurogrupo e BCE.

${ }^{10}$ Ver a Comunicação da Comissão Europeia - COM (2012) 777 de 28.11.2012.

${ }^{11}$ Este relatório (Van Rompuy, 2012), intitulado "Rumo a uma verdadeira União Económica e Monetária", retoma alguma das propostas do documento da Comissão Europeia, mas introduz desde logo algumas alterações substanciais em relação ao documento da Comissão.
} 
Salientamos as referências expressas então feitas para que os próximos passos promovessem uma solidariedade reforçada entre os membros da zona Euro, sem a qual dificilmente haveria coesão política que permitisse avançar no processo de integração. Nos documentos da Comissão e do Conselho houve menções concretas à necessidade de aa UE celebrar acordos contratuais com os Estados-Membros para promoção da competitividade e do crescimento, sendo sugerida a possibilidade de serem criados mecanismos de solidariedade que pudessem ajudar os esforços de ajustamento dos Estados que celebrem aqueles acordos.

Foi também nesta reunião que o Conselho Europeu exprimiu o seu apoio ao desenvolvimento da dimensão social na UEM, o que foi depois enfatizado na sua reunião de junho de 2013 ao salientar a importância de atender à especificidade da situação social e dos mercados laborais na zona Euro, em especial através de uma superior coordenação das políticas sociais e de emprego e do incentivo ao diálogo com os parceiros sociais. Sobre esta temática, também o Parlamento Europeu apresentou um projeto de resolução em novembro de 2012, conhecido como Relatório Thyssen e que, entre outros aspetos, recomendava explicitamente a criação de um pacto social para a Europa ${ }^{12}$.

A Comissão apresentou Comunicação ao Parlamento e ao Conselho em outubro de $2013^{13}$, onde detalha algumas iniciativas para reforçar a dimensão social da UEM, incidindo em três domínios principais: em primeiro, no reforço da monitorização e coordenação das políticas nas áreas social e do emprego; em segundo, na criação de medidas de solidariedade, de defesa do emprego e da mobilidade dos trabalhadores; em terceiro, nas formas de reforçar o diálogo social.

Pela relevância que este documento da Comissão Europeia pode ter sobre as futuras opções da UE nestas matérias, cremos ser relevante revisita-lo e discutir brevemente a viabilidade das suas propostas. Na perspetiva da Comissão, o reforço da dimensão social da UEM “(...) diz respeito à capacidade de os mecanismos de governação económica e os instrumentos políticos identificarem, considerarem e resolverem situações problemáticas e desafios relacionados com as políticas sociais e de emprego na UEM" (Comissão Europeia, 2013:4 (a)).

Desde logo, e antes de abordarmos tais mecanismos, convém ter em conta que as políticas sociais e do emprego constituem de forma substancial competências dos Estados

\footnotetext{
${ }^{12}$ Relatório de iniciativa do Parlamento Europeu intitulado «Rumo a uma verdadeira União Económica e Monetária», apresentado em 18.10.2012 e que ficou conhecido como Relatório Thyssen.

${ }^{13}$ Comunicação da Comissão ao Parlamento Europeu e ao Conselho - COM (2013) 690 final de 2 de outubro de 2013, intitulada "Reforçar a Dimensão Social na União Económica e Monetária".
} 
nacionais, os quais dificilmente encararão a possibilidade de uma transferência de poderes e de prerrogativas para a União, sem que haja uma alteração no quadro institucional vigente.

Numa primeira linha de intervenção, prosseguindo a via do reforço da estratégia de supervisão multilateral que as instituições comunitárias têm vindo a desenvolver como resposta à crise, a Comissão propõe incorporar a dimensão social no processo de supervisão dos desequilíbrios macroeconómicos ${ }^{14}$ no âmbito mais vasto do "Semestre Europeu" ${ }^{15}$, o que deverá propiciar uma superior coordenação das políticas sociais e de emprego ao nível da zona.

Em termos teóricos, a superior coordenação e supervisão destas políticas pode favorecer a convergência económica dos países que partilham a mesma moeda e corrigir alguns desequilíbrios sociais entre eles e melhorar a performance económica e a estabilidade política da zona Euro. Deste modo, a eventual colocação do Conselho de Ministros do Emprego e dos Assuntos Sociais com um estatuto e uma posição semelhante ao Conselho de Ministros de Economia e Finanças (ECOFIN) no quadro institucional da zona Euro poderá dar maior relevância e capacidade de intervenção coordenada sobre as questões sociais na UEM.

Para concretizar uma superior coordenação das políticas económicas na zona Euro, consideramos positiva a proposta de criação de um painel de indicadores de referência ${ }^{16}$, aplicado regularmente, que possa refletir um acompanhamento próximo da evolução social e nos mercados laborais, servindo como observatório para uma mais rápida deteção e análise dos problemas no domínio social e do emprego, em especial quando destes possam decorrer efeitos transfronteiriços.

Todavia, não bastará identificar os indicadores para revelar em tempo oportuno os problemas sociais, mas há que concretizar instrumentos e dispor de recursos que respondam efetivamente aos problemas detetados. Na realidade, será sempre restritivo e pouco eficaz se os mecanismos de monitorização se limitarem à observação da realidade e a identificar eventuais divergências e, em paralelo, as instituições comunitárias e os Estados-membros

\footnotetext{
${ }^{14}$ Ver Regulamento (EU) no 1176/2011 de 16 de Novembro de 2011 sobre "Prevenção e correção dos desequilíbrios macroeconómicos".

${ }^{15}$ O "Semestre Europeu" é uma iniciativa aprovada em setembro de 2010 e que configura uma das vias de resposta à crise através de um novo ciclo de coordenação ex-ante das políticas económicas e orçamentais dos Estados-membros, em articulação como o Pacto de Estabilidade e Crescimento e a Estratégia Europa 2020. Para mais informação sobre o assunto ver documento online do Conselho Europeu intitulado "O que é o Semestre Europeu", acesso em http://www.consilium.europa.eu/special-reports/european-semester?lang=pt

${ }^{16}$ A Comissão avança na COM (2013-b) 690, a título exploratório, com 5 indicadores que cobrem as seguintes áreas: alterações observadas no desemprego, percentagem de jovens que não têm emprego nem prosseguiram estudos, rendimento disponível das famílias, taxa de risco de pobreza na população ativa e níveis de desigualdade.
} 
não dispuserem de capacidade de intervenção, a qual deverá facilitar ações preventivas sobre as suas causas e reativas para a minimização dos seus efeitos negativos.

Outra via possível para atenuar os impactos dos choques económicos específicos é o reforço da mobilidade de trabalhadores entre os Estados, a fim de absorver algum desemprego. Por motivos vários, como a persistência de barreiras linguísticas e culturais, a mobilidade do trabalho na Europa tem sido reduzida, apesar da consagração legal da liberdade de circulação de trabalhadores no seio da UE após a criação do Mercado Único. Fatores como a ausência de interligação entre os sistemas nacionais de pensões, a falta de informação sobre vagas de emprego disponíveis e o reconhecimento de qualificações profissionais constituem barreiras efetivas à mobilidade laboral.

$\mathrm{Na}$ Comunicação da Comissão que vimos referindo é dado destaque às ações destinadas a intensificar a mobilidade dos trabalhadores, quer no domínio da procura, quer do lado da oferta de emprego. De facto, a mobilidade laboral, como mecanismo de regularização face aos desajustes nos mercados laborais, num contexto de livre circulação dos bens, serviços e factores, torna-se um potente mecanismo de flexibilidade no ajustamento dos mercados. Em termos de iniciativas concretas nesta área é relevante referir os progressos legislativos ocorridos para assegurar a portabilidade dos direitos adquiridos pelos trabalhadores, independentemente do país da UE em que exerçam a atividade profissional, bem como no reconhecimento das qualificações e na melhoria da informação sobre oportunidades de emprego transfronteiriças.

Por último, uma breve referência à eventual criação de um sistema europeu de proteção no desemprego, uma ideia falada há décadas e que a Comissão retomou agora na sua Comunicação. Como sustentam Dullien and Fichtner (2013) um sistema de seguro contra o desemprego teria vantagens face a outros sistemas de transferências fiscais, pois basear-se-ia na dinâmica das taxas de desemprego de curto prazo, despoletando transferências compensatórias automáticas, de acordo com a situação de cada país no ciclo económico e evitaria que os países se tornassem regularmente beneficiários ou contribuintes líquidos. Este estabilizador automático daria resposta imediata aos impactos sociais de choques económicos ao garantir um nível mínimo de proteção social.

\section{A dimensão social das reformas estruturais e a solidariedade Europeia}

Para lá das componentes até agora referidas como vias de resposta aos impactos sociais da crise na zona Euro, ancoradas na superior supervisão e coordenação das políticas, 
as instituições comunitárias têm trazido também para o debate político aspetos como a integração fiscal, a dotação de uma capacidade orçamental da UE e até a criação de eventuais mecanismos de apoio financeiro a programas de reformas estruturais para ajudar à dinamizar as economias e a suportar os custos sociais do processo de ajustamento.

Nas iniciativas tomadas pelas instituições comunitárias que antes referimos é reconhecido que as reformas estruturais dos sistemas que promovem o emprego, a competitividade e o crescimento económico são cruciais, mas que dificilmente produzirão resultados em prazos curtos. Ora, para apoiar os países sujeitos a realidades socioeconómicas de maior vulnerabilidade será crucial mobilizar financiamentos comunitários em condições favoráveis para ajudar a ação dos países na resolução de problemas como o desemprego, mormente pela formação e qualificação profissional, e pela atuação em situações de emergência social, integrando nas políticas comunitárias uma componente de solidariedade e entreajuda entre os Estados-membros.

Foi nesta conjuntura que a Comissão referiu a possibilidade de criar um instrumento autónomo no novo quadro de governação económica para apoiar medidas de reajustamento dos países, em complemento aos mecanismos de coordenação e supervisão em curso. Assim, o denominado "Instrumento de Convergência e Competitividade" (ICC) referido já em 2012 pela Comissão ${ }^{17}$, admitia a importância de dispor de capacidade orçamental para exercer alguma função de apoio à estabilização. $\mathrm{Na}$ altura, esta posição foi entendida como oportunidade para a posterior criação de um dispositivo comum para fazer face a desequilíbrios de curto prazo e à sua evolução cíclica.

A configuração deste mecanismo foi posteriormente detalhada pela Comissão ${ }^{18}$, propondo que os membros da zona Euro em maior dificuldade económica pudessem celebrar acordos que lhes permitissem aceder a um mecanismo de apoio às reformas estruturais orientadas para o estímulo à competitividade e ao crescimento. No início, o sistema seria suportado pelo quadro financeiro plurianual (QFP), podendo, a prazo, ser financiado por outro tipo de recursos, o que reforçaria a capacidade orçamental da UEM. Assim, o ICC assentaria em dois pilares: acordos contratuais que instituíam medidas com as quais os Estados se comprometiam e, como contrapartida, receberiam apoio financeiro para custear as reformas inscritas naqueles acordos ${ }^{19}$.

\footnotetext{
${ }^{17}$ Ver documento COM (2012) 777.

${ }^{18}$ Ver documento COM (2013-a) 165 de 20 de março de 2013 intitulado "Rumo a uma União Económica e Monetária efetiva e aprofundada - Introdução de um Instrumento de Convergência e Competitividade".

${ }^{19}$ Em Parecer emitido sobre a proposta de criação do ICC, o Conselho Económico e Social da União Europeia manifesta as suas dificuldades em avaliar o mérito da proposta sem que haja uma quantificação da dimensão
} 
Assumia-se, assim, que este instrumento contribuiria para aprofundar a integração da política económica com a dimensão financeira de forma a conciliar a maior responsabilidade e disciplina dos Estados com a vertente da solidariedade da UE. Sustentava, ainda que num prazo mais lato e depois de concretizar uma maior transferência de competências soberanas dos Estados para o nível central, ser desejável dispor de um orçamento independente para a zona Euro com capacidade suficiente para absorver os choques. De forma algo cautelosa a Comissão manifesta a sua preferência por um mecanismo que determine as contribuições/recebimentos de cada Estado em função das variações do seu PIB face à média da zona, evitando que situações de contribuinte ou recebedor líquido permaneçam por períodos longos, a fim de evitar efeitos políticos nocivos.

Mais recentemente, no Conselho Europeu de dezembro de 2013 aguardava-se que os líderes europeus consensualizassem algum avanço para um plano de ação mais focado e operacional sobre a dimensão social da UEM, no entanto este órgão limitou-se a referir sobre o assunto que “(...) reitera a importância da evolução no plano social e do emprego no Semestre Europeu” e prossegue salientando a continuidade dos “(...) trabalhos sobre os indicadores sociais e de emprego, na linha do que foi proposto pela Comissão...." (Conselho Europeu, 2013:20) sem apontar caminhos precisos para prosseguir tal dimensão.

Todavia, no que respeita às denominadas "Parcerias para o Crescimento, o Emprego e a Competitividade", o Conselho foi mais afirmativo e reconheceu nas suas conclusões que seria vital apoiar a realização das reformas estruturais nos Estados-membros, através de "um sistema de acordos contratuais, acompanhados de mecanismos de solidariedade correspondentes" (Conselho Europeu, 2013:17).

A posição mais controversa do Conselho nesta matéria teve a ver com o facto de ter impedido os países da zona Euro sujeitos a programas de ajustamento macroeconómico de acederem a estes apoios. O principal argumento usado foi o de que seria inútil incitar estes países a prosseguir reformas estruturais já inscritas nos programas de ajustamento a que os países se submeteram, pois já beneficiavam da solidariedade da UE. Cremos que este é um argumento algo ilusório, pois descura o facto de que os apoios que os países recebem por via dos programas de ajustamento se orientarem para a assegurar a sustentabilidade da sua dívida e não se destinam à compensação de eventuais custos suportados com a aplicação de reformas estruturais.

que o mesmo possa vir a ter, além de que expressa sérias reservas sobre a aceitação da proposta pelos Estadosmembros. A propósito, ver Projecto de Parecer do CES - ECO/348," Instrumento de Convergência e Competitividade - Principais reformas da política económica", 14 de maio de 2013. 
Permanecem ainda algumas incertezas sobre o modelo final que o instrumento possa revestir, em especial no que respeita às decisões a tomar sobre o tipo de reformas consideradas, sobre a capacidade nacional de apropriação destes programas de reformas, sobre a natureza (empréstimos, subsídios ou outro qualquer formato) e os montantes dos apoios financeiros. Ora, não obstante não detalharmos aqui estes aspectos, não podemos deixar de referir que as soluções adoptadas terão implicações sobre a real valia dos acordos para responder aos problemas revelados pelos países da zona Euro.

Alguns resultados sobre a aplicação dos programas de ajustamento mostram que estes têm tido algum sucesso na tarefa de aplicar medidas para fortalecer a competitividadepreço dos países por via da redução dos custos de produção, em especial dos salários. A maioria dos países empreendeu reformas no mercado de trabalho para introduzir mais flexibilidade e, ainda, para promover a gradual liberalização de setores específicos. Todavia, parece notório que, em geral, os países não têm conseguido, em paralelo, criar condições para atenuar o impacto social dos processos de liberalização e para melhorar a produtividade a longo prazo, sobretudo por via de políticas ativas de emprego ou pela renovação dos respetivos sistemas de ensino e formação.

De acordo com Rubio (2013), dois conjuntos de razões parecem relevantes para explicar esta situação divergente: por um lado, apesar das reformas estruturais serem cruciais para garantir a longo prazo a sustentabilidade do processo de ajustamento económico e social, a sua importância é pouco valorizada pelos mercados financeiros que assumem a perceção do risco numa ótica de curto prazo; por outro, as reformas legislativas que incidem sobre a liberalização da economia não exigem grandes recursos financeiros, ao invés do que se passa com o fortalecimento do mercado de trabalho ou a capacitação da política social, domínios que requerem recursos significativos e uma forte coordenação de distintas entidades. Assim, a escassez de recursos e a fraca coordenação é determinante para a ausência de efetivas reformas estruturais, o que justifica a existência de financiamentos específicos para apoiar esta dimensão.

Não existindo razões ponderosas para excluir os países sob programas de ajustamento do acesso como beneficiários a estes contratos de competitividade, também não parece que estes possam ser a solução ideal para o problema maior destes países. Na realidade, mais do que um sistema de incentivos para facilitar as reformas estruturais, a zona Euro poderia beneficiar com a criação de um mecanismo de assistência financeira temporária para apoiar os países a promover os ajustamentos socialmente mais exigentes, como defende Delors (2013). Tal intervenção seria justificada pelo facto de as deficiências 
na arquitetura da UEM terem contribuído também para a atual situação daqueles países, pois se a zona dispusesse de meios para sinalizar e atuar sobre as divergências de competitividade, esses países jamais teriam sido confrontados com situações tão dramáticas, exigindo intensos processos de desvalorização interna.

Este instrumento temporário seria diferente dos atuais Fundos comunitários, sendo aplicado aos países da zona Euro que estão a ser causticados pelos severos programas de austeridade e que não dispõem de condições orçamentais para implementar reformas estruturais mais dispendiosas. $\mathrm{O}$ propósito seria auxiliar estes países em divergência a tomar medidas para mitigar o impacto social negativo dos processos de liberalização e, ainda, para melhorar a produtividade e a competitividade estrutural das suas economias. Embora com objetivos diferentes dos programas da "Troika", poderiam ser estabelecidas algumas cláusulas de condicionalidade para a execução de um programa de reformas, embora de forma flexível e construtiva, na lógica do que já se aplica aos fundos estruturais e de coesão.

Em suma, os projetos de apoio financeiro aos processos de reforma estrutural nos países da zona Euro até agora apresentados pelas instituições comunitárias parecem longe de responder aos desafios de ajustamento e de estabilização com que alguns países se confrontam e têm revelado pouco empenho político dos líderes europeus. Os já referidos "acordos contratuais" de pouco servirão se forem entendidos como meros dispositivos de incentivo à aplicação de um qualquer pacote de reformas para liberalizar os mercados e não como efetivos contratos de solidariedade que promovam a disciplina, coesão e a partilha de responsabilidades.

\section{Considerações Finais}

Quando foi anunciada a criação do Euro e nos anos subsequentes muitas vozes, entre políticos e académicos, alertaram para os riscos envolvidos com a criação de uma zona monetária sem que, em simultâneo, fossem realizados progressos na via de uma maior integração fiscal e política. Porém, como o ciclo económico não trouxe percalços maiores nos primeiros anos de vida do Euro, só a atual crise económica relançou a discussão sobre os caminhos a seguir para completar a estrutura da UEM. No plano político, as instituições comunitárias assumiram que a arquitetura do Euro teria que ser reequilibrada com a inclusão de outras vertentes, declarando expressamente a necessidade de avançar para uma nova UEM "efetiva e genuína”. 
Neste contexto, começaram a aparecer com alguma naturalidade na discussão pública assuntos fundamentais para estabelecer uma nova configuração da integração económica e monetária na Europa. Assim, questões controversas como a constituição de uma União Bancária, a emissão dos designados "Eurobonds", a criação de uma união orçamental e até o eventual reforço do orçamento comum dotando-o de capacidade de intervenção foram trazidas a debate.

Mais recentemente, na sequência dos gravosos efeitos que as políticas de austeridade têm tido sobre os equilíbrios sociais em alguns países da zona Euro sob resgate financeiro e da imputação das suas causas à deficiente conceção da UEM, o reforço da dimensão social adquiriu também maior protagonismo na agenda da UE. Deste modo, de forma surpreendente, parece ter sido a crise a recolocar na agenda assuntos vitais para o aprofundamento da integração europeia.

Embora muitos daqueles debates não tenham promovido iniciativas consequentes no plano prático, em virtude das posições alemãs terem sido intransigentes em relação a alguns aspectos, foi sendo instituída uma nova governança económica na Zona Euro e na UE, por via da aplicação de regulamentação mais exigente, de uma superior monitorização das performances das economias nacionais e de uma maior coordenação ex-ante das políticas económicas e orçamentais dos Estados-membros. Em termos práticos, estes desenvolvimentos propiciaram uma gradual transferência da soberania nacional para o nível central, a qual nem sempre reflectiu uma grande preocupação comunitária com a legitimidade democrática e a responsabilização das instituições envolvidas nos processos de tomada de decisão.

Não obstante os sinais encorajadores dos primeiros relatórios sobre as vias a seguir para completar a União Monetária, à medida que os efeitos da crise foram sendo absorvidos nos países do centro europeu, tornaram-se escassas as iniciativas concretas em domínios cruciais para construir uma efetiva UEM. De facto, a preferência alemã por uma união baseada na estabilidade e no controlo do processo orçamental (Hacker, 2013) remeteu para plano secundário algumas iniciativas afloradas pela Comissão sobre questões como a união fiscal, a emissão de Dívida comum ou mesmo a criação de um fundo específico para apoiar a reestruturação da Dívida nos países em maior dificuldade.

Nestes termos, as iniciativas concretas para melhorar a arquitetura da UEM e reforçar a sua vertente social, numa ótica de maior solidariedade entre Estados, esboroaram-se em disputas inúteis nos meandros das relações de poder ao nível da União e sem resultados palpáveis. Em contrapartida, foi emergindo um conjunto de elementos de natureza 
tecnocrática, como o referido "Semestre Europeu" ou os vários pacotes legislativos para melhorar a coordenação das políticas, por via dos quais se vai ajustando o atual modelo de governação da UEM, em torno da exigência de reformas estruturais e da consolidação orçamental nos Estados-membros, de mecanismos de controlo mais rigorosos e da aplicação de sanções aos países em incumprimento.

Enquanto este modelo se vai afirmando, por via de processos burocráticoadministrativos, em que cada país trata de si e a UEM coordena e monitoriza, as vertentes da integração fiscal, da criação de uma capacidade orçamental e de aprofundamento da integração política continuam à espera de oportunidade. A inclusão da dimensão social, apenas referida em finais de 2012 numa Cimeira Europeia, foi vista como uma tentativa da França e da Comissão reequilibrarem a construção da UEM e desenvolver o modelo social europeu.

Porém, as iniciativas concretas para reforçar tal dimensão não se compaginam com o quadro subjacente ao modelo focado em exclusivo na estabilidade que tem vindo a ser construído. Naturalmente o reforço da integração fiscal e da capacidade orçamental da União para intervir de forma ativa na resolução de problemas sociais é indissociável de qualquer solução duradoura para completar o quadro de governação numa União Monetária que se aproxime das condições que Mundell entendia como ótimas.

As instituições comunitárias continuam amarradas aos limites estabelecidos nos Tratados e aos temores do "risco moral" das transferências financeiras baseadas num orçamento comum e não têm revelado soluções criativas e mobilizadoras que permitam reverter o crescente sentimento de descrença no projeto europeu. Todavia, deverão ter presente que uma desintegração social e económica no seio da União terá certamente custos muito mais elevados do que os inerentes à implementação dos mecanismos que consolidem a estabilidade social e política da UE.

A inclusão de uma dimensão social de natureza horizontal, a qual deve estar presente em todas as vertentes do processo de integração e nas políticas que o concretizam, é condição fulcral para construir uma Europa mais competitiva e também mais solidária. Relembramos aqui as sábias palavras de Schuman com as quais iniciámos esta breve reflexão quando considerava que só com realizações concretas e mecanismos que traduzam uma solidariedade de facto é que podemos aspirar a uma nova Europa. Este é o momento de agarrar a oportunidade de dar um novo rumo nas políticas comunitárias e na plena assunção das responsabilidades dos Estados-membros. 


\section{Referências}

AMARAL, J. - Porque devemos sair do Euro: o divórcio necessário para tirar Portugal da

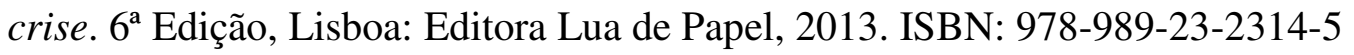

ANGELONI, Chiara; MERLER, Silvia; WOLFF, Guntram - Policy Lessons from the Eurozone Crisis. The International Spectator, Vol. 47, No. 4, December (2012) p. 17-34. [Consultado 3 de Abril de 2014]. Disponível em WWW:

<URL http://www.tandfonline.com/doi/abs/10.1080/03932729.2012.733180>. ISSN: 03932729 print; ISSN: 1751-9721 em linha

BORSI, Mihály; METIU, Norbert - The evolution of economic convergence in the European Union. Deutsche Bundesbank. Discussion Paper No 28 (2013). [Consultado 3 de Abril de 2014] Disponível em WWW:

<URL:http://www.bundesbank.de/Redaktion/EN/Downloads/Publications/Discussion_Paper _1/2013/2013_08_13_dkp_28.pdf?_blob=publicationFile>

BLANCHARD, Olivier J. - Adjustment with the Euro: The Difficult Case of Portugal. Portuguese Economic Journal. Vol. 6, Issue 1, pp. 1-21 (2007). [Consultado 3 de Abril de 2014]. Disponível em WWW:

<URL:http://download.springer.com/static/pdf/750/art\%253A10.1007\%252Fs10258-0060015-4.pdf?auth66=1397831172_62e4492111eb5d135cf9f03d7974db11\&ext=.pdf>

CAETANO, José; SOUSA, Miguel - A herança de Maastricht: das suas condicionantes às perspetivas de sustentabilidade da UEM a longo prazo. Revista Debater a Europa, Periódico do CIEDA e do CEIS20, em parceria com GPE e a RCE. N. 6 janeiro/junho, Semestral, 2012 [Consultado em 3 de Abril de 2013]. Disponível em WWW: <URL:http://www.europe-direct-aveiro.aeva.eu/debatereuropa/> ISSN 1647-6336

CENTRO DE ESTUDOS SOCIAIS - A Anatomia da Crise: Identificar os problemas para construir as alternativas: Apresentação do primeiro relatório do Observatório sobre Crises e 
Alternativas. Centro de Estudos Sociais da Universidade de Coimbra. 2014. [Consultado em 3 de Abril de 2014]. Disponível em WWW:

<URL:http://www.ces.uc.pt/ficheiros2/files/Relatorio_Anatomia_Crise_final__pdf>

COMISSÃO EUROPEIA - Reforçar a Dimensão Social da União Económica e Monetária. COM (2013) 690 de 2 de outubro (2013-b). [Consultado em 3 de Abril de 2014]. Disponível em WWW:

$<$ URL:http://eur-

lex.europa.eu/LexUriServ/LexUriServ.do?uri=COM:2013:0690:FIN:PT:PDF>

COMISSÃO EUROPEIA - Rumo a uma União Económica e Monetária efetiva e aprofundada - Introdução de um Instrumento de Convergência e Competitividade. Documento COM (2013) 165 de 20 de março (2013-a). [Consultado em 3 de Abril de 2014]. Disponível em WWW:

$<$ URL:http://eur-

lex.europa.eu/LexUriServ/LexUriServ.do?uri=COM:2013:0165:FIN:PT:PDF>

COMISSÃO EUROPEIA - Plano Pormenorizado para uma União Económica e Monetária Efetiva e Aprofundada. Lançamento de um Debate a Nível Europeu. COM (2012) 777 de 28 de novembro (2012). [Consultado em 3 de Abril de 2014]. Disponível em WWW: <URL:http://eur-lex.europa.eu/resource.html?uri=cellar:6ed5f706-fda6-492c-895b4b5e8a25648a.0014.03/DOC_1\&format=PDF>

COMISSÃO EUROPEIA - Prevenção e Correção dos Desequilíbrios Macroeconómicos. Regulamento (EU) no 1176/2011 de 16 de Novembro (2011). [Consultado em 3 de Abril de 2014]. Disponível em WWW: <URL:http://eurlex.europa.eu/LexUriServ/LexUriServ.do?uri=OJ:L:2011:306:0025:0032:PT:PDF>

COMITÉ ECONÓMICO e SOCIAL - Parecer ECO/348: Instrumento de Convergência e Competitividade - Principais reformas da política económica. 14 de maio (2013). [Consultado em 3 de Abril de 2014]. Disponível em WWW:

<URL:http://www.toad.eesc.europa.eu/ViewDoc.aspx?doc=ces\%5Ceco\%5Ceco348\%5CPT \%5CCES3043-2013_00_00_TRA_PAC_PT.doc\&docid=2918400> 
CONSELHO DA UNIÃO EUROPEIA - EUCO 217/13: Conselho Europeu de 19 / 20 de dezembro de 2013 - Conclusões. 20 de dezembro (2013). [Consultado em 3 de Abril de 2014]. Disponível em WWW:

<URL:http://www.consilium.europa.eu/uedocs/cms_data/docs/pressdata/pt/ec/140270.pdf>

CONSELHO DA UNIÃO EUROPEIA - EUCO 104/2/13: Conselho Europeu de 27 / 28 de junho de 2013 - Conclusões. 28 de junho (2013). [Consultado em 3 de Abril de 2014]. Disponível em WWW:

<URL:http://www.consilium.europa.eu/uedocs/cms_data/docs/pressdata/pt/ec/137660.pdf>

CONSELHO DA UNIÃO EUROPEIA - EUCO 205/12: Conselho Europeu de 13 / 14 de dezembro de 2012 - Conclusões. 14 de dezembro (2012). [Consultado em 3 de Abril de 2014]. Disponível em WWW:

<URL: http://www.consilium.europa.eu/uedocs/cms_data/docs/pressdata/pt/ec/134370.pdf>

CONSELHO DA UNIÃO EUROPEIA - Documento 17271/08: Conselho Europeu de Bruxelas de 11 e 12 de dezembro de 2008 - Conclusões da Presidência. 13 de fevereiro (2009). [Consultado em 3 de Abril de 2014]. Disponível em WWW:

$<$ URL:https://infoeuropa.eurocid.pt/opac/?func=service\&doc_library=CIE01\&doc_number= 000041518\&line_number=0001\&func_code=WEB-FULL\&service_type=MEDIA $>$

DE GRAUWE, Paul - The Governance of a Fragile Eurozone. CEPS. Working Document No. 346, (2011). [Consultado em 3 de Abril de 2014]. Disponível em WWW:

<URL:http:Ilwww.ceps.eu/ceps/download/5523>

DELORS, Jacques - Repenser L'UEM et "Repositiver" La Grande Europe. Tribune, Notre Europe - Institut Jacques Delors, juillet (2013). [Consultado em 3 de Abril de 2014]. Disponível em WWW:

<URL:http://www.notre-europe.eu/media/uemgrandeeurope-delors-ne-ijdjuin13.pdf?pdf=ok>

DULLIEN, Sebastian; FICHTNER, Ferdinand - A Common Unemployment Insurance System for the Euro Area. DIW Economic Bulletin, 1.2013, (2013) pp. 9-14. [Consultado em 3 de Abril de 2014]. Disponível em WWW: 
<URL:https://www.diw.de/documents/publikationen/73/diw_01.c.413714.de/diw_econ_bull _2013-01_2.pdf>

EICHENGREEN, Barry; WYPLOSZ, Charles - The Stability Pact: more than a minor nuisance?. CEPR \& CES \& MSH. Economic Policy, Vol. 13(26), pp. 65-113 (1998). [Consultado em 3 de Abril de 2014]. Disponível em WWW: <URL:http://www.aueb.gr/users/kalyvitis/Wyplosz.pdf>

EUROPEAN COMMISSION - EU Employment and Social Situation: Key Facts and Figures. Special edition, September (2013). [Consultado em 3 de Abril de 2014]. Disponível em WWW:

<URL:http://www.qren.pt/np4/np4/?newsId=3794\&fileName=ESSQR_Sept_2013_main_do c_final_rev2.pdf>

EUROPEAN COMMISSION - One market, one Money - An evaluation of the potential benefits and costs of forming an economic and monetary union. European Economy. No. 44, October (1990). [Consultado em 3 de Abril de 2014]. Disponível em WWW:

<URL:http://ec.europa.eu/economy_finance/publications/publication7454_en.pdf>

FERNANDES, Sofia; MASLAUSKAITE, Kristina - A Social Dimension for the EMU: Why and How?. Policy paper - 18, September (2013). [Consultado em 3 de Abril de 2014]. Disponível em WWW:

<URL:http://www.notre-europe.eu/media/socialdimensionsforeumfernandesmaslauskaitenejdisept2013.pdf?pdf $=$ ok $>$

FERREIRA, Paulo; CAETANO, José - Integração Financeira Incompleta: zona Euro em Cheque? Revista Debater a Europa. N. 8 janeiro a julho, p. 65 - 86 (2013). [Consultado em 3 de Abril de 2014]. Disponível em WWW:

<URL:http://europe-direct-aveiro.aeva.eu/debatereuropa/images/n8/pferreira_jcaetano.pdf>

HACKER, Bjorn - On the Way to a Fiscal or a Stability Union? The Plans for a "Genuine" Economic and Monetary Union. Friedrich-Ebert-Stiftung Berlin, December, (2013). [Consultado em 3 de Abril de 2014]. Disponível em WWW: <URL:http://library.fes.de/pdffiles/id/ipa/10400.pdf> 
LAEVEN, L.; VALENCIA, F. - Systemic Banking Crises Database: An Update. IMF Working Paper 12/163 (2012). [Consultado em 3 de Abril de 2014]. Disponível em WWW: <URL:http://tvernedra.ru/GlobaliRegionRiski.pdf>

MASLAUSKAITE, Kristina - Social Competition in the EU: Myths and Realities. Studies and Reports - Notre Europe. Le 05 Juin (2013). [Consult. 3 de Abril de 2014]. Disponível em WWW: <URL:http://www.notre-europe.eu/media/socialcompetition-maslauskaite-nejdi-june13.pdf?pdf=ok>

MUNDELL, Robert - A Theory of Optimum Currency Areas. AEA: The American Economic Review, Vol. 51, No. 4 Setembro., (1961), pp. 657-665. [Consultado em 3 de Abril de 2014]. Disponível em WWW: <URL: http://www.jstor.org/stable/1812792 > ISSN: 0002-8282.

PARLAMENTO EUROPEU - Relatório 2012/2151 (INI) - Recomendações à Comissão sobre Relatório "Rumo a uma verdadeira União Económica e Monetária". 18 de outubro (2012). [Consultado em 3 de Abril de 2014]. Disponível em WWW:

<URL:http://www.europarl.europa.eu/sides/getDoc.do?pubRef=\%2f\%2fEP\%2f\%2fTEXT\% 2bREPORT\%2bA7-2012-

0339\%2b0\%2bDOC\%2bXML\%2bV0\%2f\%2fPT\&language=PT\#title1>

PISANI-FERRY, Jean; SAPIR, André; WOLFF, Guntram - EU-IMF assistance to euro-area countries: an early assessment. Bruegel Blueprint. 2013/1, (2013). [Consultado em 3 de Abril de 2014]. Disponível em WWW:

<URL:http://www.bruegel.org/publications/publication-listing/category/2-blueprints/>

PISANI-FERRY, Jean; SAPIR, André; WOLFF, Guntram - An evaluation of IMF surveillance of the euro area, Blueprint 14, Brussels: Bruegel (2011). [Consultado em 3 de Abril de 2014]. Disponível em

<URL:http://www.bruegel.org/publications/publication-detail/publication/629-anevaluation-of-imf-surveillance-of-the-euro-area/> 
ROMPUY, Van - Rumo a uma Verdadeira União Económica e Monetária. Relatório do Presidente do Conselho Europeu, Bruxelas, 26 de junho (2013). [Consultado em 3 de Abril de 2014]. Disponível em WWW:

<URL:http://www.consilium.europa.eu/uedocs/cms_data/docs/pressdata/pt/ec/131292.pdf>

RUBIO, Eulalia - Quel instrument financier pour faciliter les réformes structurelles dans la zone euro?. Policy paper Notre Europe, (2013). Disponível em WWW: <URL:http://www.notre-

europe.eu/media/aidefinancirereformestructurellesemu.pdf?pdf $=\mathrm{ok}>$

SCHUKNECHT, L.; MOUTOT, P.; ROTHER,P.; STARK, J. - The Stability and Growth Pact: Crisis and Reform. European Central Bank, Occasional Paper, n. 129; September, (2011). [consultado 3 de Abril de 2013]. Disponível em WWW:

<URL: http://www.ecb.int/pub/pdf/scpops/ecbocp129.pdf >. ISSN: 1725-6534.

THE ECONOMIST - European Economy Guide: Taking Europe's Pulse. (2014). [Consultado a 3 de Abril de 2014]. Disponível em WWW:

<URL:http://www.economist.com/blogs/graphicdetail/2014/03/european-economy-guide>

VÉRON, Nicolas - Is Europe ready for a major banking crisis?. Policy Brief 2007/03, Bruegel (2007). [Consultado em 3 de Abril de 2014]. Disponível em WWW:

<URL:http://www.bruegel.org/publications/publication-detail/publication/234-is-europeready-for-a-major-banking-crisis/> 